\title{
Detection of people in military and security context imagery (withdrawal notice)
}

Thomas Shannon, Ben Wiltshire, Emmet Spier

Thomas M. L. Shannon, Ben Wiltshire, Emmet H. Spier, "Detection of people in military and security context imagery (withdrawal notice)," Proc. SPIE 9248, Unmanned/Unattended Sensors and Sensor Networks X, 92480N (17 October 2014); doi: 10.1117/12.2069906

SPIE. Event: SPIE Security + Defence, 2014, Amsterdam, Netherlands 


\title{
Detection of people in military and security context imagery (withdrawal notice)
}

\author{
Proc. SPIE 9248, 92480N (2014) \\ Online Publication Date: 17 October 2014 \\ Withdrawn from Publication: 7 November 2014 \\ Conference Date: 24-25 September 2014 \\ Conference Location: Amsterdam, Netherlands \\ Conference Title: Unmanned/Unattended Sensors and Sensor Networks X \\ Conference Chairs: Edward M. Carapezza, Panos G. Datskos, Christos Tsamis
}

Thomas M. L. Shannon, Ben Wiltshire, Emmet H. Spier

2d3 Sensing (United Kingdom)

This paper has been withdrawn by the publisher because it was already published in the following volume:

Electro-Optical Remote Sensing, Photonic Technologies, and Applications VIII; and Military Applications in Hyperspectral Imaging and High Spatial Resolution Sensing II

The correct record for this manuscript can be found here:

http://dx.doi.org/10.1117/12.2071902 